\title{
Sífilis congénita: Optimizando el diagnóstico en 191 neonatos de madres seropositivas
}

\author{
ALEJANDRA REYES J., GONZALO CHORBADJIAN A., M. ANGÉLICA PARADA C., \\ JENNY TURRYS C., NIEVES BRAVO C. y CARMEN G. ARAYA F.
}

\section{Congenital Syphilis: Optimizing the diagnosis in 191 newborn infants of VDRL positive mothers}

Congenital syphilis is still an important issue in terms of public health. In this prospective study the change in case definition and treatment of congenital syphilis, as well as the addition of a third VDRL to a pregnant woman at her admission to hospital, allowed to improve the detection of congenital syphilis cases to improve, specially in the group of mothers who were infected at the third trimester of pregnancy or close to delivery. In a five-year period (1994-1999) 191 newborn infants of VDRL (+) mothers were studied in the nursery and their clinical and serological (VDRL and FTA-ABS) follow-up was conducted during 15 months. Congenital syphilis was documented in 6/6 cases of the presumptive congenital symptomatic syphilis group and in $3 / 24$ cases $(12,5 \%)$ in the asymptomatic presumptive syphilis group. No cases were detected in asymptomatic newborn children whose mother had received opportune and adequate syphilis treatment during gestation. Decisions made based on epidemiologic, serologic and clinical records of the mother and her newborn child, are a valid choice to identify those children who are at greater risk of Treponema pallidum infection. This is while there is no specific and sensitive routine diagnostic test available to discard the illness in asymptomatic newborn children, especially when it is not possible to assure a long term follow up.

Key words: Congenital Syphilis; Diagnosis; Treatment.

Palabras claves: Sífilis congénita; Diagnóstico; Tratamiento.

\section{Introducción}

La sífilis congénita sigue constituyendo, en nuestro país, un problema relevante de salud pública. Desde fines de los años 80 se ha reportado un aumento de los casos de esta enfermedad. En Chile, las tasas observadas entre 1990 y 1997 aumentaron de 0,23 a 0,34 por 1.000 recién nacidos $(\mathrm{RN})^{1}$.

La sífilis congénita se produce luego de una infección transplacentaria por Treponema pallidum. Las etapas primaria y secundaria de la infección se caracterizan por altas concentracio- nes de espiroquetas circulantes en el torrente sanguíneo de las mujeres embarazadas, por lo cual, el riesgo fetal es muy elevado ${ }^{2,3}$.

El riesgo teórico de infección fetal en las etapas primaria y secundaria de la sífilis es de 90 a $100 \%$. En 50\% de los casos producirá abortos, mortinatos, partos prematuros y muertes neonatales, manifestándose en el 50\% restante como una sífilis congénita. Posteriormente, el riesgo de infección cae a $80 \%$ en la etapa latente precoz y a menos de $50 \%$ transcurrido un año o más de infección materna ${ }^{4,5}$.

El $60 \%$ de los RN infectados nace asinto-

Hospital Félix Bulnes Cerda:

Servicio de Pediatría, Unidad de Infectología (ARJ).

Servicio de Ginecología y Obstetricia (MAPC, JTC, NBC).

Laboratorio VDRL y Laboratorio Central (CGAF).

Estudiante de Medicina, Universidad de Santiago de Chile (GChA).

Recibido: 18 noviembre 2003

Aceptado: 7 julio 2004 
mático, manifestando la enfermedad en las primeras semanas o meses de vida. Se describen secuelas en 1 a $3 \%$ de los pacientes tratados.

El diagnóstico de sífilis congénita es difícil de confirmar, no disponiéndose en la actualidad de un método rápido, sensible y específico que asegure el diagnóstico en los RN, especialmente en aquellos que nacen asintomáticos.

Desde 1993 se incorporó en nuestra maternidad un tercer test de VDRL a la madre y se modificó el manejo de los RN, hijos de madres con serología positiva, Para realizar esta modificación, nos basamos en las recomendaciones del CDC de Atlanta, E.U.A., que permiten definir, tratar y notificar los casos de sífilis congénita al nacer, con mayor claridad que lo recomendado por el Ministerio de Salud de Chile.

Nos pareció de interés mostrar nuestra experiencia en 6 años de aplicación de estos nuevos criterios.

\section{Objetivos}

- Evaluar la norma de manejo y seguimiento de los RN en riesgo de sífilis congénita, hijos de madres VDRL (+) durante el embarazo.

- Mejorar la pesquisa de sífilis congénita incorporando un tercer VDRL en la madre, al momento del parto.

\section{Pacientes y Método}

Ingresaron a este estudio todos los $\mathrm{RN}$, hijos de madres que tuvieran VDRL positivo durante el embarazo, nacidos en la Maternidad del Hospital Dr. Félix Bulnes Cerda entre los años 1994 y 1999. A través de una anamnesis detallada se averiguó los antecedentes maternos, los tests de VDRL realizados durante la gestación y los tratamientos recibidos. Por norma, al ingreso a la Maternidad se realizó un nuevo VDRL a todas las mujeres embarazadas seropositivas y en aquellas sin determinación serológica durante los últimos 3 meses de embarazo, completándose el estudio con FTA-ABS (Fluorescent treponemal antibody absorption) o MHA-TP (Microhemagglutination assay for antibodies to Treponema pallidum) y test de ELISA para VIH.

Basándonos en las definiciones del $\mathrm{CDC}^{6}$ que se señalan en la Tabla 1, se modificó la definición de sífilis congénita, aplicándose la norma de manejo detallada en la Figura 1. En la Tabla 2 se mencionan los criterios para considerar como adecuado, el tratamiento de la sífilis en la mujer embarazada.
Tabla 1. Definiciones del CDC Atlanta para sífilis congénita

\section{- Caso confirmado}

RN o lactante en que se identifica $T$. pallidum en la placenta, cordón umbilical o autopsia

\section{- Caso presuntivo}

- Hijo de madre con sífilis no tratada o inadecuadamente tratada al momento del parto, independiente de los síntomas

- RN con serología positiva asociada a: Evidencias de sífilis congénita al examen Radiografía de huesos largos alterada VDRL (+) en LCR

Aumento de células y proteínas en el LCR no atribuible a otra causa IgM FTA-ABS 19S positiva

\section{- Aborto sifilítico}

Muerte fetal con más de 20 semanas de gestación o peso mayor de 2.500 grs si al parto, la madre tiene sífilis no tratada o fue inadecuadamente tratada

Los RN con sífilis congénita presuntiva (SCP) fueron estudiados y tratados en la Unidad de Neonatología. El estudio incluyó: evaluación clínica, VDRL en sangre periférica, FTA-ABS o MHA-TP estudio citoquímico y VDRL en LCR, hemograma, pruebas hepáticas, examen de orina, ecocardiografía, test de ELISA para VIH, radiografía de huesos largos y de cráneo.

Todos los RN con SCP recibieron penicilina sódica en dosis de 100.000 UI kg/día vía intravenosa, durante 10 a 14 días.

Posteriormente fueron controlados con VDRL al mes de edad y cada 2 meses hasta el año de vida. Después de los 15 meses se realizó FTAABS o MHA-TP para confirmar o descartar el diagnóstico de sífilis congénita. En los niños que tuvieron alteraciones citoquímicas y/o VDRL (+) en el LCR, se repitió el estudio a los 6 meses y al año de vida.

Los RN de bajo riesgo (BR) y de muy bajo riesgo (MBR) de sífilis congénita fueron controlados en el policlínico de TORCH con evaluación clínica y VDRL al mes, 2, 4 y 6 meses de edad, realizándose FTA-ABS o MHA-TP después de los 15 meses de vida.

Al nacer se tomó FTA-ABS o MHA-TP a todos los $\mathrm{RN}$ que ingresaron al protocolo de seguimiento.

Para el análisis final se excluyeron los pacientes que no completaron el seguimiento y los falsos positivos del embarazo corroborado por FTA-ABS o MHA-TP negativo en la madre. 


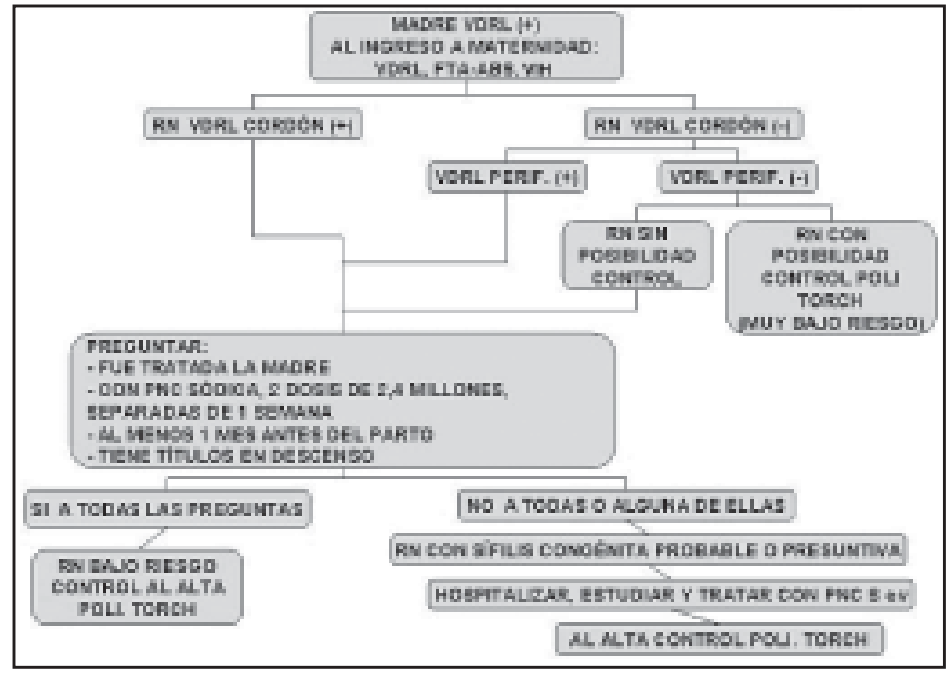

Tabla 2. El tratamiento adecuado de la sífilis en la mujer embarazada se define como:

- Haber sido tratada única y exclusivamente con penicilina benzatina 2.400.000U, 2 dosis con un intervalo de una semana

- Haber sido tratada un mes antes del parto

- Tener seguimiento serológico que muestre títulos en descenso

- Al comparar con las determinaciones previas, no tener al momento del parto, aumento del VDRL en 2 diluciones

Figura 1. Algoritmo de manejo de los RN hijos de madres VDRL (+).

\section{Resultados}

Durante el período de estudio $191 \mathrm{RN}$ completaron el seguimiento y fueron clasificados en tres grupos:

- RN con sífilis congénita presuntiva (n: 30 ).

- RN con bajo riesgo de sífilis congénita (n: 121).

- RN con muy bajo riesgo de sífilis congénita (n: 40).

Se excluyeron $10 \mathrm{RN}$, hijos de madres con pruebas treponémicas negativas, considerados como falsos positivos del embarazo.

$R N$ con sífilis congénita presuntiva. En este grupo, 24 (80\%) fueron asintomáticos (SCPA) y $6(20 \%)$ sintomáticos (SCPS). En los RN con SCPS se encontraron las siguientes manifestaciones de enfermedad: retardo del crecimiento intrauterino (2); neurosífilis (3), de las cuales, un caso presentó VDRL (+) con aumento de la celularidad y proteínas en el LCR; lesiones óseas (3); visceromegalias (3); lesiones de piel (1). El análisis de los antecedentes maternos mostró que: $4(13,4 \%)$ casos correspondieron a embarazos no controlados, en $15(50 \%)$ se detectó viraje del VDRL en los tres últimos meses del embarazo, $2(6,6 \%)$ recibieron eritromicina, 5 $(16,6 \%)$ fueron tratadas con penicilina benzatina (PNB) menos de 1 mes antes del parto, $1(3,4 \%)$ recibió una sola dosis de $\mathrm{PNB}$, en $1(3,4 \%)$ paciente se planteó reinfección y en $2(6,6 \%)$ casos las madres no fueron tratadas.

El título de VDRL en sangre periférica en los pacientes con SCPS al momento del diagnóstico, fue de 1:2 o más, observándose en 4 de ellos títulos de 1:16 o superiores. En los casos de SCPA los títulos fueron iguales o menores a 1:4.

El seguimiento serológico demostró que ningún caso de SCPS negativizó el VDRL antes de los 3 meses de edad, en $4(66,6 \%)$ niños fue negativo a los 6 meses, y en $2(33,3 \%)$ después de los 6 meses de edad. En los pacientes con SCPA, el VDRL se negativizó en $13(54,1 \%)$ casos antes de los 3 meses y los 24 (100\%) niños presentaron VDRL negativo a los 6 meses de vida. El seguimiento serológico con pruebas treponémicas después de los 15 meses de vida confirmó el diagnóstico de sífilis congénita en los $6(100 \%)$ niños con SCPS y en $3(12,5 \%)$ con SCPA.

En los pacientes que presentaron VDRL positivo en LCR al nacer, catalogados como neurosífilis, fue verificada la negativización del VDRL en LCR a los 6 meses y al año de vida.

$R N$ con bajo riesgo de sífilis congénita. En este grupo, probablemente con serología positiva por traspaso de anticuerpos maternos, los títulos de VDRL en sangre de cordón fueron en 108 $(89,2 \%)$ casos iguales o menores a 1:2, en 2 RN el VDRL en sangre de cordón fue negativo, observándose títulos menores de 1:2 en el VDRL de sangre periférica.

El seguimiento serológico demostró que en 95 niños $(78,5 \%)$ el VDRL se negativizó antes de 3 meses y en $100 \%$ a los 4 meses de vida.

En todos ellos los anticuerpos antitreponémicos (FTA-ABS o MHA-TP) fueron negativos después de los 15 meses de edad.

$R N$ con muy bajo riesgo de sífilis congénita. En este tercer grupo, con VDRL en sangre de 
cordón y periférico (-), mantuvieron el VDRL (-) en $100 \%$ de los casos y en todos ellos las pruebas treponémicas fueron negativas a los 15 meses de edad. El análisis de los antecedentes maternos mostró que en $36(90 \%)$ casos las madres recibieron tratamiento adecuado durante el embarazo, 4 (10\%) no cumplieron con este criterio, 1 fue tratada menos de 1 mes antes del parto y 3 recibieron sólo una dosis de PNB. Los títulos de VDRL en $100 \%$ de las madres fueron menores de 1:2 al momento del parto.

En todas las pacientes a las que se le realizó test para VIH (n: 189), éste resultó negativo.

\section{Discusión}

Si bien la infección, por T. pallidum, se transmite al feto en cualquier etapa del embarazo, no es responsable de malformaciones congénitas. Se ha observado que el tratamiento en la mujer embarazada, antes de las 20 semanas de gestación, previene la enfermedad en el feto, no así, cuando se realiza después de este período donde no se previenen las secuelas. Sería necesaria la presencia de una respuesta inmunológica para producir daño en el feto ${ }^{1,7}$. En la mujer embarazada el tratamiento con penicilina benzatina (PNB) permite evitar la transmisión vertical; Nathan y col demostraron la necesidad de administrar dos dosis de PNB, con un intervalo de una semana, para lograr la erradicación del T. pallidum ${ }^{8}$, sin existir en la actualidad otras alternativas terapéuticas superiores. La eritromicina no previene la transmisión transplacentaria9 .

La mayoría de los RN infectados son asintomáticos al nacer, desarrollando la enfermedad en las siguientes semanas, especialmente entre la segunda y sexta semana de vida. La forma de presentación clínica de la sífilis congénita precoz, es polimorfa y hay que tenerla presente dentro del diagnóstico diferencial de otras patologías.

Treponema pallidum no puede ser cultivado y la detección de espiroquetas en muestras de fluidos mediante microscopia de campo oscuro, es de baja sensibilidad en los RN. El test de capacidad infectante en conejos es de alto costo y se realiza en laboratorios de investigación ${ }^{10}$.

Los test serológicos empleados en el diagnóstico de sífilis, tanto los no treponémicos: VDRL, RPR (Rapid plasma reagin) y los treponémicos: FTA-ABS y MHA-TP detectan IgG e IgM. Durante el embarazo, especialmente en el último trimestre, se produce paso de IgG a través de la placenta, de tal forma que una serología positiva en el RN no nos permite diferenciar entre el traspaso pasivo de anticuerpos maternos y la infección del RN.

La detección de IgM positiva en la madre no está relacionada con un mayor riesgo de sífilis congénita. Los tests de IgM realizados en el RN tienen buena especificidad y son útiles para el diagnóstico precoz de sífilis congénita, pero no permiten descartar el diagnóstico cuando el resultado es negativo.

La RPC como método diagnóstico de sífilis congénita, tiene una sensibilidad de $94 \%$ en suero o sangre y de $65 \%$ en LCR, pero no es una técnica disponible para su uso habitual en nuestro medio $^{10}$.

No disponemos de un test que nos permita descartar definitivamente el diagnóstico de sífilis congénita en la etapa de recién nacido, por lo cual, la decisión de iniciar el tratamiento específico debe basarse en la evaluación de los antecedentes epidemiológicos, serológicos y clínicos del binomio madre-hijo.

Esta evaluación nos permitió realizar el diagnóstico en $100 \%$ de los RN con SCPS y en $12,5 \%$ de los RN con SCPA, lo que fuera confirmado por la presencia de anticuerpos antitreponémicos después de los 15 meses de vida.

En esta serie de pacientes, se catalogaron como neurosífilis 2 casos que sólo tuvieron VDRL (+) en LCR. Si bien este criterio es controvertido, está descrito que el compromiso del SNC es frecuente en los casos de sífilis congénita y es la razón por la cual, el único tratamiento recomendado para la sífilis congénita es con penicilina sódica (PNS) endovenosa. El VDRL tiene una baja sensibilidad en el LCR, pero su asociación con alteraciones en el citoquímico, como el aumento en la celularidad y las proteínas, se ha correlacionado significativamente con la identificación de $T$. pallidum, por test de capacidad infectante en conejos ${ }^{11}$.

El $50 \%$ de las madres de los RN con sífilis congénita presuntiva se infectaron en el tercer trimestre del embarazo o en un período cercano al parto. Esto reafirma la necesidad de realizar un tercer VDRL durante el embarazo, como una medida tendiente a disminuir y mejorar la pesquisa de los casos de sífilis congénita, estando en la actualidad incluido en la normativa ministerial vigente $^{12}$. La sífilis congénita es una enfermedad prevenible en la mujer embarazada, mediante la pesquisa con tests no treponémicos, de un costo menor si se compara con el tratamiento y seguimiento de los niños que desarrollan la infección.

La determinación de anticuerpos antitreponémicos a los 15 meses fue negativa en $100 \%$ de 
los RN catalogados de bajo riesgo y de muy bajo riesgo al nacer. Por lo tanto, la evaluación de los antecedentes del binomio madre-hijo permite seleccionar al grupo de $\mathrm{RN}$ con mayor riesgo de presentar una sífilis congénita. Esto representa una alternativa válida para la toma de decisiones, hasta no contar con un método diagnóstico sensible y específico de uso rutinario, que permita descartar la enfermedad, especialmente en los RN que nacen asintomáticos.

Es necesario tener presente, que la serología negativa en la madre y en el RN no descarta la infección por $T$. pallidum, especialmente si la madre adquirió la infección en un período cercano al parto ${ }^{14}$. Se debe considerar que el título de anticuerpos tarda algunas semanas en elevarse. También se describe que una determinación serológica puede ser falsamente negativa por un fenómeno de prozona (altas concentraciones de anticuerpos pueden dar floculación inaparente).

En el segmento de MBR, los antecedentes del binomio madre-hijo de un pequeño grupo arrojaron que las madres no habían sido adecuadamente tratadas. Ante la certeza de poder realizar seguimiento clínico y serológico, no se realizó terapia antimicrobiana, descartándose posteriormente la infección en estos pacientes.

Es necesario considerar, que en los casos de $\mathrm{RN}$ seronegativos y asintomáticos con una evaluación del binomio madre-hijo que no cumpla con las condiciones de un adecuado tratamiento materno, debería realizarse la terapia específica al RN, especialmente si no se puede asegurar su seguimiento posterior al alta de la maternidad. Estos recién nacidos no pueden ser catalogados con bajo riesgo de sífilis congénita, modificación que se introdujo en la norma de manejo, a partir del año $2000^{12}$.

\section{Resumen}

La sífilis congénita sigue siendo un problema importante de salud pública. En este estudio prospectivo, los cambios en la definición y manejo de la sífilis congénita, así como la incorporación de un tercer VDRL tomado a la mujer embarazada a su ingreso a la maternidad, permitieron mejorar la pesquisa de los casos de sífilis congénita, especialmente en el grupo de madres que se infectaron en el tercer trimestre del embarazo o en un período cercano al parto. En un período de 5 años (1994-1999) se estudiaron al nacer y efectuó seguimiento clínico serológico con VDRL y FTA-ABS hasta los 15 meses de vida a 191 neonatos hijos de madre VDRL (+). Se documentó la sífilis congénita en $6 / 6$ pacientes en el grupo con sífilis congénita presunta sintomática y en $3 / 24$ casos $(12,5 \%)$ del grupo con sífilis presunta asintomática. Ningún neonato asintomático cuya madre recibiera oportuno y correcto tratamiento de sífilis durante la gestación desarrolló la enfermedad. La toma de decisiones basada en los antecedentes epidemiológicos, serológicos y clínicos del binomio madre-hijo, es una alternativa válida para identificar al grupo de RN con mayor riesgo de presentar la infección por Treponema pallidum, mientras no se cuente con un test diagnóstico de uso rutinario, sensible y específico, que permita descartar la enfermedad en el RN asintomático, especialmente cuando no se pueda asegurar un seguimiento posterior.

\section{Bibliografía}

1.- Ministerio de Salud. Boletín ETS. Boletín Epidemiológico $N^{\circ} 2$ Enfermedades de Transmisión Sexual. Chile. Mayo 2000.

2.- Beck-Sague C, Alexander E. Sexually transmitted diseases in children and adolescents. Infect Dis Clin North Amer 1987; 1: 277-80.

3.- Berry M, Dajani A. Resurgence of congenital syphilis. Infect Dis Clin North Am 1987; 6: 19-29.

4.- Chávez A, Rojas C, Rakela S, Navarro E, Palma L, Urra L. Sífilis congénita en el Servicio de Salud Metropolitano Sur. Pesquisa de casos. Rev Chil Infect 1997; 14: 42-8.

5.- Salazar A, Perret C, Chávez A, García C, Millán Z. Evaluación de métodos diagnósticos para sífilis congénita. Rev Chil Infect 2000; 17: 289-96.

6.- Zenker P, Berman S M. Congenital syphilis: trends and recommendations for evaluation and management. Pediatr Infect Dis J 1991; 10: 516-22.

7.- Zegpi M S, Norero M. Sífilis congénita precoz. Dermatol Chile 1995; 11: 88-90.

8.- Nathan L, Bawdon P. Penicillin levels following the administration of benzathine penicilin $\mathrm{G}$ in pregnacy. Obstet Gynecol 1993; 82: 338-42.

9.- Dabanch J. Sífilis. Rev Chil Infect 2000; 17 (Supl 1): 62-5.

10.- Larsen S, Pope V, Johnson R, Kennedy E. Manual of Test for Syphilis $9^{\mathrm{a}}$ Edition. American Public Health Association- Washington D C, 1998, p 1- 361.

11.- Michelow I J, Wendel G D Jr, Norgard M V, Zeray F, Leos N K, Alsaadi R, et al. Central nervous system infection in congenital syphilis. N Engl J Med 2002; 346 (23): 1792-8

12.- Ministerio de Salud. Normas de manejo de ETS. 2000.

13.- Walker D G, Walker G J. Forgotten but not gone: the continuing scourge of congenital syphilis. Lancet Infect Dis 2002; 2 (7): 432-6.

14.- Sánchez P J, Wendel G D, Norgard M V. Congenital syphilis associated with negative results of maternal serologic tests at delivery. Am J Dis Child 1991; 145 (9): 967-9.

Correspondencia a:

Alejandra Reyes Jiménez

infecciosofelix@yahoo.es 